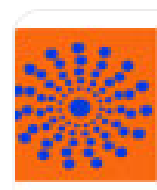

JOURNAL OF BEHAVIOR, HEALTH \& SOCIAL ISSUL

minst

Quiroga Baquero, Luis Alberto; Padilla Vargas, María Antonia EL CONCEPTO DE MODO LINGÜÍSTICO Y SU APLICACIÓN EN LOS PROCESOS DE ENSEÑANZA-APRENDIZAJE MEDIANTE LAS TIC'S

Journal of Behavior, Health \& Social Issues, vol. 6, núm. 1, mayo-octubre, 2014, pp. 9-22 Asociación Mexicana de Comportamiento y Salud, A. C.

Distrito Federal, México
Journal of Behavior, Health \& Social Issues

ISSN: 2007-0780

jcpedro@unam.mx

Asociación Mexicana de Comportamiento y

Salud, A. C.

México

Disponible en: http://www.redalyc.org/articulo.oa?id=282231041001

Cómo citar el artículo

- Número completo

- Más información del artículo

- Página de la revista en redalyc.org 


\title{
EL CONCEPTO DE MODO LINGÜÍSTICO Y SU APLICACIÓN EN LOS PROCESOS DE ENSEÑANZA-APRENDIZAJE MEDIANTE LAS TIC'S
}

\author{
THE CONCEPT OF LINGUISTIC MODES AND THEIR APPLICATION \\ TO TEACHING-LEARNING PROCESSES USING ICTS
}

\author{
Luis Alberto Quiroga Baquero \\ Fundación Universitaria Konrad Lorenz, Bogotá, \\ Colombia. \\ María Antonia Padilla Vargas \\ Centro de Estudios e Investigaciones en \\ Comportamiento \\ Universidad de Guadalajara, México
}

\begin{abstract}
Recibido: Abril 1, 2013
Revisado: Mayo 18, 2013

Aceptado: Agosto 22, 2013

Los autores agradecen a los revisores anónimos las invaluables sugerencias que han permitido enriquecer significativamente el presente documento. Cualquier comunicación dirigirla a: Luis Alberto Quiroga Baquero. Fundación Universitaria Konrad Lorenz. Carrera 9 Bis No. 62 - 43. Bogotá, Colombia. Tel. (+57 1) 34723 11, correo electrónico: laquirogabđunal.edu.co
\end{abstract}

\section{Resumen}

El objetivo del presente escrito es describir la geografía lógica del concepto de modo lingüístico con el fin de identificar sus usos particulares en los dominios funcionales del lenguaje ordinario y del lenguaje técnico para finalmente caracterizar su pertinencia en los ámbitos del conocimiento analítico y sintético. Se pretende mostrar cómo el concepto de modo lingüístico puede ser útil en la producción de conocimiento sintético ya que puede aplicarse tanto en niveles de análisis del desarrollo conductual como en niveles multi e interdisciplinares, lo que puede hacerse evidente en el contexto específico de los procesos de enseñanza-aprendizaje, y particularmente en el diseño, desarrollo y aplicación de herramientas tecnológicas como el caso concreto de las Tecnologías de la Información y la Comunicación (TIC's). Se analizan estudios empíricos realizados con el objeto de identificar la efectividad de los modos lingüísticos: leer-dibujar-escribir-hablar, y ver-escuchar, y lo que los resultados muestran de manera consistente es que: 1) a mayor cantidad de modos lingüísticos implicados mejor desempeño, y 2) primacía del modo visual respecto del auditivo. Además, se analizaron diferentes estudios con el objeto de comparar la efectividad de las TIC's como herramientas didácticas y lo que se encontró fue que sólo se han realizado estudios en los que se compara la exposición de los participantes a textos impresos versus textos multimedia. En estos trabajos también se han encontrado hallazgos consistentes: la ejecución es similar pero los participantes prefieren leer textos en formato multimedia. Aunque solo se ha analizado sistemáticamente un modo lingüístico (leer) y únicamente en dos modalidades (textos impresos versus multimedia), los hallazgos sugieren que las TIC's son herramientas didácticas efectivas y eficientes. Se requiere analizar los otros modos lingüísticos comparando su efectividad con las herramientas multimedia en función de las competencias académicas que se espera que los estudiantes adquieran.

Palabras Clave: Modo lingüístico, enseñanza-aprendizaje, Tecnologías de la Información y la Comunicación, herramientas didácticas. 
Abstract

The present article attempts to describe the logical geography of the concept of linguistic mode. We first identify its particular uses within the functional domains of the ordinary language and technical language, and then we characterize its pertinence within the domains of analytic and synthetic knowledge. In addition, we try to show that the concept of linguistic mode can be useful for the production of synthetic knowledge, because it can apply to both the levels of analysis of behavioral development and the multi and interdisciplinary levels, which can be evidenced in the context of teaching-learning processes in general, and in the design, development, and application of technological tools in particular, such as the concrete case of the Information and Communication Technologies (ICT's). Studies carried out to assess the effectiveness of the linguistic modes (reading-drawing-writing-talking and seeing-listening) were analyzed and the results consistently showed that: 1) performance is enhanced with a greater the number of linguistic modes, and 2) there is a primacy of the visual mode over the auditory. In addition, we analyzed studies that compared the effectiveness of ICTs as didactical tools and found only comparisons between printed versus multimedia materials. These studies also yield consistent results: performance is similar between media, but participants prefer multimedia texts. Although only one linguistic mode (reading) has been studied extensively and only two types of media (printed versus multimedia) have been compared, these results suggest that ICTs are effective and efficient didactic tools. Further research on other types of linguistic modes and their relationship to multimedia tools and the competencies expected from a student is necessary.

Key words: Linguistic mode, teaching-learning, Information and Communication Technologies, didactic tools.

\section{Introducción}

\section{Antecedentes}

Es un hecho que a lo largo de los últimos siglos ha habido una proliferación en el diseño, desarrollo y uso de tecnologías que han ampliado y transformado las prácticas sociales entre individuos y concretamente las formas o modos en que las interacciones lingüísticas ocurren. El desarrollo industrializado de la imprenta durante el siglo $\mathrm{XV}$, de la televisión y la radio en el siglo XIX, del teléfono, las computadoras, los dispositivos móviles de comunicación y las demás Tecnologías de la Información y la Comunicación (TIC's), han auspiciado que los seres humanos desarrollen formas de interacción lingüística con otros individuos y con artefactos, que trascienden la mera oralidad, gesticulación y escritura cuneiforme que caracterizaba tales interacciones en las primeras civilizaciones humanas.

En la actualidad, las distintas formas de ocurrencia del lenguaje que comprenden el hablar, escribir, gesticular, señalar, observar, leer y es- cuchar en diversas circunstancias institucionales (e. g., ámbitos educativos, organizacionales, científicos, familiares, etc.), implican en muchas ocasiones la interacción con y a través de artefactos que posibilitan contactos lingüísticos con múltiples variaciones en las condiciones de tiempo y espacio que circunscriben la situación de interacción y con múltiples combinaciones en que dichas formas de ocurrencia se presentan de manera sucesiva y/o concurrente. Esta diversidad de posibilidades en que pueden ocurrir las interacciones lingüísticas ha estimulado la investigación científica en distintas disciplinas cuyo interés compartido ha sido el estudiar cómo tales formas de expresión del lenguaje afectan las relaciones que establecen los individuos con los objetos y eventos lingüísticos del ambiente (e. g., Aaron \& Malatesha-Joshi, 2006; Chafe \& Tannen, 1987; Hawe, Dixon \& Watson, 2008; Mahony, Singson \& Mann, 2000; Petty, 1974). 


\section{El empleo de las TIC's en los procesos de enseñanza-aprendizaje}

En los últimos años cada vez es más frecuente, en las instituciones educativas, el empleo de las TIC's en los procesos de enseñanza-aprendizaje, con el objeto de dar respuesta, por un lado, a las necesidades de cobertura en relación con la demanda que el mercado de este tipo de servicios impone; y por otro, para ofrecer alternativas novedosas y efectivas en el diseño, aplicación y evaluación de materiales didácticos con fines pedagógicos y formativos. Sin embargo, resalta que en este ámbito específico de desarrollo tecnológico se ha privilegiado la producción de materiales de apoyo (e. g., materiales multimedia, en formato impreso, digital, etc.) como auxiliares de los procesos de enseñanza-aprendizaje en los diversos niveles de formación y se ha descuidado sistemáticamente su vinculación con el conocimiento acumulado de orden analítico proveniente de disciplinas científicas tales como la sociología, la fonoaudiología, la lingüística, la neurolingüística, la psicología, la antropología, entre otras, que fundamente tal desarrollo tecnológico; en concreto, el conocimiento científico disciplinar y las soluciones prácticas tecnológicas en el ámbito de la educación no evidencian un desarrollo paralelo. Las implicaciones de ello se esbozarán a continuación.

Ribes (1989a) señala que el conocimiento de orden analítico corresponde al conocimiento científico disciplinar strictu sensu. Su característica principal es que se abstrae, a través de un proceso de análisis, de las circunstancias y eventos concretos que constituyen su universo de investigación. En este sentido, el conocimiento analítico describe relaciones abstraídas entre eventos y relaciones concretas, pero sus conceptos no se refieren a tales eventos o circunstancias concretas. Por otra parte, el conocimiento sintético corresponde al conocimiento científico tecnológico. Se caracteriza por describir ocurrencias particulares, operaciones, resultados y circunstancias concretas. Mediante un proceso de síntesis se hace posible que a partir de las categorías analíticas de una o varias disciplinas, se describan eventos y circunstancias concretas, condiciones y procedimientos de operación y criterios de predicción y control de tales eventos singulares. Este autor resalta que en la construcción de conocimiento sintético en cualquier dominio que caracterice problemas socialmente relevantes, se hace indispensable la vinculación entre categorías analíticas de una o varias disciplinas científicas, el desarrollo de herramientas tecnológicas en su sentido más amplio, y el saber práctico propio de las relaciones cotidianas de los individuos en estas circunstancias sociales.

Es común entonces, encontrar una gran cantidad de herramientas tecnológicas vinculadas como soportes pedagógicos, los cuales, en la mayoría de los casos, no evidencian una fundamentación en términos del conocimiento analítico multi e interdisciplinar que valide su aplicabilidad en contexto, su efectividad en el proceso enseñanzaaprendizaje y su contribución en la mejora de la calidad de la formación académica.

Uno de los casos excepcionales de vinculación sistemática entre conocimiento analítico y conocimiento sintético se refleja en el campo de las ciencias cognitivas con la teoría de carga cognitiva de John Sweller y colaboradores (Sweller, 2005a; Sweller, 2005b) y la teoría cognitiva del aprendizaje multimedia de Richard Mayer y colaboradores (Mayer, 2001; Mayer \& Moreno, 1998; Moreno \& Mayer, 1999; Moreno \& Mayer, 2000), las cuales han influido el campo del diseño instruccional de materiales didácticos en el ámbito educativo a través de la identificación de un conjunto de principios que describen el proceso de aprendizaje a través de TIC's y, por ende, permiten la creación de ambientes de aprendizaje virtual más eficientes.

El desarrollo conceptual y experimental en estas dos líneas de investigación ha permitido identificar de qué manera el aprendizaje es facilitado u obstaculizado por las características morfológicas de los elementos lingüísticos (visuales o auditivos) empleados; en concreto, si los individuos aprenden mejor un contenido particular si se combinan modos de presentación de la información como texto y audio, audio e imágenes, imágenes y audio o cualquier otra combinación posible. A través de estudios experimentales, han logrado plantear algunos principios explicativos acerca del cuándo y por qué un determinado tipo de material multimedia facilita el aprendizaje, a saber: (a) Principio multimedia: se aprende mejor 
con palabras e imágenes que con sólo palabras; (b) Principio de contigüidad espacial: se aprende mejor cuando las palabras y las imágenes se presentan cercanas entre sí que cuando están lejos en la página o pantalla; (c) Principio de contigüidad temporal: se aprende mejor cuando las palabras y las imágenes se presentan de manera simultánea que sucesiva; (d) Principio de coherencia: se aprende mejor cuando no hay que procesar imágenes o palabras extrañas en la memoria de trabajo; (e) Principio de modalidad: se aprende mejor cuando una animación se acompaña con texto oral que con texto impreso; y (f) Principio de redundancia: se aprende mejor con animaciones acompañadas por texto oral que por texto oral y escrito, con la misma información (Kaptelinin, 2004).

Desde esta postura, los efectos de las modalidades de presentación de la información se abordan con base en un modelo de análisis serial de procesamiento de información. La recepción de la información a través de las entradas sensoriales y su posterior paso a la memoria sensorial permitiría que el individuo interactué con las características físico-químicas de los elementos lingüísticos a través de la audición, la visión o el tacto. Así mismo, la codificación (semántica o perceptual) que recibe esa información al pasar de la memoria sensorial a la memoria de corto plazo y de ésta última a la memoria a largo plazo, permitirá determinar efectos diferenciales sobre la recuperación de ésta.

\section{Los modos lingüísticos desde la perspectiva del Análisis de la Conducta}

Por otra parte, en el campo del análisis de la conducta no se encuentra un abordaje sistemático ni a nivel teórico ni metodológico en el que se estudien las interacciones lingüísticas en sus diferentes formas o modos de ocurrencia. Desde la postura skinneriana (e. g., Skinner, 1957), los modos del lenguaje son abordados parcialmente al definir las operantes verbales, principalmente debido a las limitaciones de las categorías conceptuales que sustentan un análisis operante del lenguaje como comportamiento (para una revisión extensa de dichas limitaciones consultar Ribes, 1999).

Las operantes verbales descritas por Skinner (1957) se clasifican con base en las correspondencias entre clases de estímulo y clases de respuestas; en el caso de los tactos, los mandos y las intraverbales, si son hablados, escritos o gesticulados no es relevante debido a que pueden pertenecer a una misma clase. Por otra parte, en el caso de los comportamientos ecoicos y textuales, su mismo nombre indica a qué modos del lenguaje corresponderían. En el estudio del episodio verbal que propone Skinner (1957) se desprenden dos niveles de análisis: uno descriptivo relacionado con la topografía de la respuesta verbal (principalmente del hablante) y otro nivel relacionado con la explicación, referido a las condiciones de adquisición y modificación; es decir, de la identificación de las variables de las cuales es función la conducta verbal y de las relaciones funcionales de las cuales hacen parte las operantes verbales. En síntesis, las diferencias funcionales de estos modos de lenguaje estarían dadas por las relaciones de contingencia a las que se encuentran vinculados.

Esta caracterización skinneriana acerca del comportamiento verbal en términos de una triple relación de contingencia (antecedente-respuestaconsecuente), supone una correspondencia morfológica entre el estímulo discriminativo y la respuesta operante verbal, la cual, al ser definida como una operante en tanto que cause un efecto sobre el ambiente y éste a su vez afecte funcionalmente al organismo, permite asumir que conductas como hablar, escribir señalar y gesticular sean aquellas objeto de estudio psicológico en tanto que producen efectos, así sea indirectos, sobre el ambiente, de lo cual se desprende que las conductas de observar y escuchar no correspondan con la definición de operante, en tanto que no ejercen ninguna acción efectiva sobre el ambiente (Pérez-Almonacid \& Quiroga, 2010).

El abordaje que ofrece Skinner (1957) acerca de la conducta verbal constituye uno de los desarrollos más sobresalientes en el campo del conocimiento analítico que aborda los eventos conductuales lingüísticos desde la perspectiva del análisis experimental del comportamiento; sin embargo, no resultó en una propuesta que promoviera el desarrollo experimental sistemático de los procesos conductuales implicados en la adquisición y modificación del comportamiento verbal; ni tampoco, en el estudio de las impli- 
caciones de dichos procesos en la solución de problemas socialmente relevantes en situaciones institucionales (e.g., diseño y aplicación de TIC's en ámbitos educativos).

Es posible plantear entonces, dos cosas: la primera, que las categorías analíticas a través de las cuales se estudia la conducta verbal desde una perspectiva operante son el resultado de "un ejercicio en interpretación más que una extrapolación cuantitativa de resultados experimentales rigurosos" (Skinner, 1957, p. 22); y segundo, que el desarrollo de conocimiento sintético fundamentado en tales categorías analíticas es escaso, lo que permite evidenciar que el objetivo del autor, en sus palabras, de que dicha "formulación es intrínsecamente práctica y sugiere aplicaciones tecnológicas inmediatas casi en cada estadio" (Skinner, 1957, p. 22) no se ha logrado.

\section{Los modos lingüísticos desde \\ la perspectiva Interconductual}

Una excepción en el análisis conceptual y experimental de las diversas formas de ocurrencia del lenguaje tanto en el nivel de conocimiento analítico como del sintético en el ámbito del análisis de la conducta la constituye el modelo interconductual derivado de los planteamientos de Kantor (1967/1978) y Ribes y López (1985). Desde esta perspectiva se han abordado las interacciones con y a través del lenguaje y en la forma de lenguaje, fundamentándose en una concepción de la interconducta lingüística y en particular en el desarrollo teórico y experimental acerca del concepto de modos lingüísticos.

Con el fin de describir el ámbito funcional del concepto de modos lingüísticos en el campo del conocimiento analítico y sintético de una disciplina psicológica, se presentará un análisis de su uso tanto en los dominios del lenguaje ordinario como en el del lenguaje técnico de la historia natural y de la teoría científica a partir de la propuesta presentada por Ribes (2009, 2010), según la cual es posible identificar cinco niveles secuenciales de construcción y aplicación de la ciencia, identificando en cada uno de ellos la geografía lógica a partir de la cual se predica la pertinencia y funcionalidad de los términos que componen orgánicamente el universo de lo psicológico.

En dicha propuesta se enfatiza en primer lugar la importancia de distinguir entre lenguaje técnico y lenguaje ordinario dado que las funciones de cada uno se ajustan a la naturaleza o lógica de sus propósitos, por lo que el uso apropiado de cada tipo de lenguaje es necesario para prevenir caer en confusiones categoriales. Es justamente con base en dicha distinción que Ribes (2009) elabora una clasificación de los cinco niveles categoriales que considera recorren las ciencias en su proceso de construcción y aplicación del conocimiento sobre el mundo: 1) el primero inicia en el mundo del "conocimiento ordinario, cotidiano, compartido socialmente por todos los individuos mediante el lenguaje respecto de las cosas, acontecimientos y acciones que se experimentan directamente" (p. 15); 2) el segundo implica la identificación de regularidades en las formas con que se interactúa cotidianamente, "condición necesaria para poder construir de manera explícita y sistemática un lenguaje teórico, que abstraiga las observaciones y manipulaciones sobre los acontecimientos y objetos del mundo de sus particularidades" ( $p$. 15); 3) en el tercero el lenguaje tiene como función describir las formas de las distintas regularidades observadas en el punto previo promoviendo la visibilidad de nuevas regularidades y formas no identificadas previamente dado el carácter no analítico del lenguaje ordinario; 4) el cuarto nivel es el primer punto de retorno de la teoría hacia el mundo cotidiano, pero con ciertas características especiales ya que consiste en el uso de "las categorías de un cuerpo teórico para interpretar un conjunto de observaciones de otro campo disciplinario (multidisciplina) o de observaciones propias del nivel de la historia natural; es decir, de regularidades empíricas que deben identificarse e interpretarse a partir de la teoría disciplinar" ( $p$. 15); y 5) finalmente, el quinto constituye el retorno al mundo cotidiano compartido por el lenguaje ordinario, con fenómenos vinculados a objetos, acontecimientos y circunstancias particulares. Sin embargo, en este punto, a diferencia del primer nivel, los fenómenos observados son interpretados como casos de principios generales descritos por la teoría científica dado que implica "identificar las propiedades particulares involucradas en un fenómeno determinado, y dar cuenta de éste en términos del conocimiento teórico-experimental sobre dichas propiedades en circunstancia" (p.15). 
Empleando la propuesta previa como herramienta analítica se intentará mostrar cómo el concepto de modo lingüístico ha ido transitando del primer al último nivel adquiriendo con ello el estatus de un término técnico. Como ya se mencionó, en el primer nivel, el dominio del lenguaje ordinario corresponde con la naturaleza fenoménica de la disciplina; en el caso particular de la psicología, al dominio del uso cotidiano y ordinario de los términos mentalistas que describen lo que un organismo hace o lo que le ocurre en circunstancia. El concepto de modo lingüístico tiene su origen (al igual que cualquier otro concepto) en las prácticas del lenguaje ordinario, en las cuales se utilizan expresiones del tipo piensa antes de hablar, yo pienso mejor escribiendo, yo le hablaré a "Mengano", estaba hablando conmigo mismo, escribiré una carta, te estoy escuchando, lee mentalmente o lee en voz alta, háblame con señas, etc. Este tipo de expresiones denotan en su uso cotidiano formas o modos en que el lenguaje acontece como instrumento y como ocurrencia (Ribes, 2006); hacen referencia al ámbito de la morfología y la funcionalidad del lenguaje. En tanto que dichas expresiones solo tienen sentido en las circunstancias particulares en que tienen lugar, las expresiones referidas a las formas de ocurrencia del lenguaje no denotan el componente observable o de exteriorización de procesos mentales internos, como en el caso de expresiones del tipo "lee mentalmente" o "piensa antes de hablar" como si el hablar fuera una forma de actuar o de hacer externo lo interno que sería el pensar; más bien, el uso del término hablar en esa expresión se refiere a un modo particular del pensar, a una forma particular de ocurrencia del pensar como evento lingüístico psicológico.

Un uso particular de estos términos se encuentra en aquellas circunstancias en las cuales se denotan capacidades y competencias como por ejemplo "ya sé escribir en inglés", "puedo hablar en lenguaje de señas" o "fui capaz de leer entre líneas". Estos usos específicos refieren a disponibilidades acerca del saber hacer con y a través del lenguaje, de competencias lingüísticas específicas en relación a la morfología que define la modalidad de ocurrencia.

Si bien los términos hablar, escribir, señalar, observar, leer y escuchar son términos del lenguaje ordinario y presentan significados multívocos dependiendo de las situaciones específicas en que son usados, el concepto de modo lingüístico corresponde a un término técnico que se abstrae de las ocurrencias o circunstancias concretas en que el lenguaje acontece y cuyo significado pretende ser unívoco. En un segundo nivel, el lenguaje técnico de la historia natural permite reconocer semblanzas entre las entidades y los acontecimientos cotidianos, clasificándolos con base en las regularidades entre sus formas (Ribes, 2009, 2010). Aunque puede recoger términos del lenguaje ordinario para clasificar instancias o relaciones, también puede emplearse para crear nuevos términos o trasladar términos de otras disciplinas, siempre delimitando su uso a las circunstancias específicas de aplicación y evitando así un uso problemático o incompatible en relación con otros conceptos emparentados.

El concepto de modo lingüístico como término técnico de la historia natural permite entonces clasificar formas de ocurrencia del lenguaje en circunstancias socialmente definidas. Hablar, escuchar, leer, escribir, señalar, gesticular y observar corresponden al hacer actuativo con y a través del lenguaje (Ribes, 2007), de carácter específico en los seres humanos, permitiendo así excluir aquellas expresiones del tipo "mi perro me habla o me escucha". En tanto que las formas de las cuales se predica su regularidad corresponden a expresiones del lenguaje ordinario, Ryle (1949/2005) provee un conjunto de herramientas conceptuales, que se utilizarán a continuación, para identificar las semblanzas de familia entre diferentes expresiones referidas a las ocurrencias del lenguaje; en sus palabras: "determinar la geografía lógica de los conceptos es poner de manifiesto la lógica de las proposiciones que los contienen, o sea, mostrar qué proposiciones son congruentes o incongruentes con ellas, cuáles se siguen de ellas y de cuáles se infieren. El tipo lógico o categoría al que pertenece un concepto es el conjunto de modos o maneras en que se lo puede usar con legitimidad lógica" (p. 7).

Según Ribes (2007), aprender un lenguaje equivale a aprender sus distintos modos de ocurrencia; hablar, leer, escribir, observar y gesticular corresponderían a términos de logro en tanto que hacen referencia directamente a resultados; decir que "sé hablar inglés" o que "sé guiñar el ojo" 
corresponden a usos del hablar o guiñar que implican por necesidad la satisfacción de criterios. Por otra parte, pueden corresponder a términos adverbiales cuando en su uso se refieren a cualificaciones de acciones, por ejemplo, cuando se dice que "escribía pensando en ti", no es que se escriba y se piense por separado, sino que se escribe de una manera, o que se piensa de una determinada forma. Finalmente, los modos lingüísticos leer, escribir, hablar y gesticular pueden corresponder a términos de acción en aquellos usos que identifican actividades o respuestas como formas de conducta directas y discretas.

Asumir el concepto de modo lingüístico como categoría analítica abstraída de las regularidades de los eventos lingüísticos concretos permite comprender su funcionamiento y estructura. En otros términos, la estructura lógica de un sistema teórico como es el caso de la taxonomía propuesta por Ribes y López (1985), fundamenta el uso de términos técnicos como el que compete a este escrito, constituyendo así el cuerpo de conocimiento analítico de una disciplina psicológica; en términos de Ribes (2010), en el tercer nivel de construcción y aplicación de conocimiento científico, "la teoría científica (y los términos técnicos que la conforman orgánicamente) constituye, en lo esencial, un instrumento para identificar fenómenos, para reorganizar conceptualmente fenómenos ya identificados, para orientar sobre el tipo de descripciones y explicaciones factibles, y para guiar el diseño y formulación de métodos y procedimientos observacionales y experimentales congruentes con la lógica del sistema propuesto" (p. 60).

Así, el concepto de modo lingüístico correspondería en sentido estricto, a un término técnico específico de una teoría científica psicológica, en este caso, de una Teoría de la Conducta (Ribes \& López, 1985). Fuentes y Ribes (2001) suponen que el concepto de modo lingüístico corresponde a una categorización de formas o modos conductuales relacionados con la práctica lingüística, los cuales son desarrollados ontogenéticamente y son distinguibles entre sí por su morfología; es decir, por un lado por el medio de ocurrencia que los caracteriza, y por otro lado por los sistemas reactivos implicados.

Proponen que dichos modos lingüísticos pue- den ser divididos en dos categorías: productivos (señalar, gesticular, hablar y escribir), en tanto que se generan o producen objetos de estímulo con morfología y funcionalidad convencional, y reactivos (observar, escuchar y leer) dado que constituyen las formas o modos de ocurrencia del contacto funcional con tales objetos y eventos de estímulo. Los segundos suministran una retroalimentación con respecto de los primeros promoviendo su efectividad y precisión, y se presentan como antecedentes ontogenéticos de los modos productivos. Asimismo, los modos lingüísticos entendidos como díadas funcionales (activo-reactivo) presentan propiedades funcionales diferenciales que afectan los procesos conductuales de adquisición y desarrollo de competencias lingüísticas en diferentes niveles de organización del comportamiento (Fuentes \& Ribes, 2001; Irigoyen, Jiménez \& Acuña, 2008; Mares, 2001). Por ejemplo, en el caso de los modos lingüísticos, se ha observado un fenómeno denominado habilitación, definida como el conjunto de condiciones que permiten la emisión de una respuesta bajo una modalidad activa cuando el contacto con los eventos de estímulo se ha presentado bajo modalidades reactivas. La evidencia experimental recabada a la fecha, empleando tareas de igualación a la muestra de primer orden, ha mostrado que todas las modalidades reactivas habilitan la respuesta de escribir como respuesta de igualación; sin embargo, se observó un mayor nivel de habilitación del modo observar al escribir en comparación con las demás modalidades, mientras que leer y escuchar mostraron un nivel de habilitación semejante (Tamayo, Ribes \& Padilla, 2010). Ribes (2007) afirma que la participación diferencial de los distintos modos lingüísticos (reactivos y activos) en el aprendizaje resulta en distintos tipos de conocimiento, y por ende, en diferentes tipos de competencias conductuales. El conocimiento de orden declarativo se desarrollaría a partir de la participación de los modos reactivos en las situaciones de aprendizaje, mientras que el conocimiento de orden actuativo estaría vinculado a los modos activos en tanto que corresponde a acciones en las situaciones de aprendizaje. En este mismo sentido, Camacho (2006) y Gómez (2005) proponen que la adquisición de los modos 
lingüísticos y de las competencias lingüísticas a éstos vinculadas, dependen de las propiedades funcionales de cada uno, determinadas por la arbitrariedad de la morfología de los eventos de estímulo y de las respuestas correspondientes; en concreto, que los modos señalar-observar presentarían una menor arbitrariedad en sus morfologías, y por ende, una mayor facilidad de adquisición y que los modos leer-escribir presentarían una mayor dificultad de adquisición y ejercicio en virtud de que comprenden morfologías más complejas, específicas y precisas.

Estas propiedades funcionales específicas de cada modo lingüístico promoverían, como atributo disposicional, grados diferenciales de desligabilidad que probabilizarían el desarrollo y la transferencia de competencias lingüísticas en diferentes niveles de organización de la conducta (contextuales, suplementarios, selectores, sustitutivos referenciales y no referenciales [Ribes \& López, 1985]); por ejemplo, los modos leer-escribir promoverían grados de desligabilidad mayores en función de la arbitrariedad de sus morfologías, lo cual probabilizaría el desarrollo y la transferencia de competencias en niveles sustitutivos referenciales y no referenciales, lo que no sería facilitado por los modos observar-señalar.

En síntesis, la descripción del lenguaje técnico de la teoría científica correspondería al conocimiento de orden analítico propuesto por Ribes (1989a), según el cual "los términos técnicos que conforman el lenguaje de las diversas ciencias, aun cuando parten de los eventos y circunstancias concretas que enmarcan la práctica del lenguaje ordinario, no describen dichos eventos y circunstancias. Los hechos de la ciencia son siempre abstracciones de eventos concretos. La ciencia es descriptiva de relaciones abstraídas y jamás persigue la descripción de eventos singulares..." (p. 848).

Por otra parte, el cuarto nivel de la propuesta de Ribes (2010), de fundamentación y construcción de la ciencia corresponde a la aplicación de la teoría científica en el análisis de los fenómenos psicológicos en distintos niveles de concreción, particularmente en el ámbito de la solución de problemas socialmente relevantes. Los términos técnicos que constituyen la teoría científica posibilitan la comprensión de fenómenos particulares en contextos, ambientes o situaciones concretas, suponiendo entonces dos tipos de aplicaciones: internas y externas. En el caso de las aplicaciones internas, los términos técnicos permiten abordar experimentalmente los procesos que dan cuenta del desarrollo psicológico, desarrollo concebido como "la secuenciación, entrelazamiento y ramificación de los diversos procesos generales en el ajuste de cualquier individuo a un ambiente ecológico y cultural específico" (p. 61). Las aplicaciones externas por su parte, pueden darse en dos niveles: uno relacionado con la intersección de distintas disciplinas sobre un problema social pero concebido desde lógicas distintas, que comprendería así las indagaciones multidisciplinarias en las que cada componente disciplinar aportaría aspectos conceptuales o metodológicos relevantes; y dos, un nivel interdisciplinar que constituiría las denominadas profesiones, en donde se conjugan diferentes disciplinas científicas, tecnologías y saberes prácticos para intentar dar solución a problemas socialmente reconocidos. Este nivel de desarrollo en las disciplinas científicas constituye fundamentalmente el campo del conocimiento sintético, delimitado por la particularidad o concreción de sus fenómenos bajo estudio.

El concepto de modo lingüístico, en este sentido, es útil en la producción de conocimiento sintético y su aplicabilidad tanto en los niveles de análisis del desarrollo conductual, como en niveles de aplicabilidad multi e interdisciplinar, se hace evidente en el contexto específico de los procesos de enseñanza-aprendizaje y particularmente, como se ha mencionado a lo largo del texto, en el diseño, desarrollo y aplicación de herramientas tecnológicas (e. g., TIC's) en tal contexto.

En el caso concreto del estudio del desarrollo conductual, Ribes (2007) supone que las competencias que se generan a partir de los intercambios lingüísticos dependen de los modos en que tienen lugar tales interacciones. El concepto de competencia, desarrollado por Ribes, Moreno y Padilla (1996) a la luz del análisis del comportamiento inteligente (Ribes, 1989b; Ribes \& Varela, 1994), propone su identificación a partir de un conjunto de morfologías de respuesta o habilidades que guardan correspondencia o pertinencia funcional respecto de un conjunto de propiedades de eventos y objetos, a partir del cumplimiento de un 
criterio de logro impuesto por las características de los objetos con los que se interactúa, y por las demandas sociales que definen la funcionalidad de una determinada conducta como ajuste a una situación. Por ejemplo, el hablar puede corresponder a una simple repetición literal ecoica de una morfología de estímulo vocal producida por otro o por el mismo sujeto, o puede corresponder a una respuesta convencional emitida ante la mediación de un segmento lingüístico de otro individuo o del mismo, que transforma la situacionalidad aparente atribuyendo propiedades convencionales no aparentes.

Siguiendo lo anterior, el desarrollo ontogenético del individuo social implica una evolución psicológica, en tanto que comprende cambios cualitativos en las competencias que éste adquiere relacionadas con el saber hacer con y a través del lenguaje. Estas competencias se refieren en primera instancia a un aprender aquello con lo cual se aprende, es decir, aprender acciones en un medio social: observar, escuchar, señalar, gesticular, hablar, y posteriormente aprender a leer, escribir, a percibir y a interactuar con el mundo lingüístico. En segunda instancia, aprender aquello sobre lo cual se aprende, en concreto, aprender las funcionalidades de las propias acciones, de las palabras, de los eventos y de las cosas en función de las prácticas sociales históricamente establecidas del grupo social de pertenencia. En tercera instancia, aprender diversas formas de hacer con lo que se aprende, es decir, aprender a utilizar el lenguaje en sus diferentes formas (gesticulando, hablando, escribiendo) para obtener resultados; y finalmente, en una cuarta instancia, un aprender a hacer sobre el hacer, lo que implica adquirir competencias que posibiliten interactuar con los propios productos lingüísticos; hablar, escribir o gesticular sobre lo que se hace, dice o escribe e inclusive modificar el comportamiento de otros o el propio sobre lo que se hace o dice (Ribes, 2007).

En este sentido, los modos lingüísticos, en tanto ocurrencias, permitirían tener contacto empírico con las competencias lingüísticas en situaciones sociales específicas, como lo afirma Ribes (2006): "ser competente, por consiguiente, se refiere a que se puede hacer algo porque ya se ha hecho o porque se tiene conocimiento de lo que se tiene que hacer" (p. 20). Lo que un individuo aprende a hacer con el lenguaje en situación determinará su ejecución en situaciones similares o diferentes como una tendencia a comportarse en una nueva situación, como si se estuviera en la situación inicial de aprendizaje (Varela \& Quintana, 1995).

\section{La aplicación de los modos lingüísticos a los procesos de enseñanza-aprendizaje mediante las TIC's}

La aplicabilidad del concepto de modo lingüístico a nivel multi e interdisciplinar puede hacerse evidente en el campo de la educación a través del estudio de las interacciones lingüísticas con y a través de las TIC's. En este sentido, se han venido desarrollando un conjunto de investigaciones desde la perspectiva teórica del modelo interconductual, procurando dar cuenta de las dimensiones funcionales de los modos lingüísticos en los procesos de enseñanza-aprendizaje.

Un ejemplo concreto de ello lo presentan Irigoyen, Jiménez y Acuña (2006), quienes intentaron evaluar si los modos lingüísticos leer-señalar y leer-escribir promovían ajustes diferenciales en el comportamiento de estudiantes universitarios, procurando vincular el estudio de los modos lingüísticos en las interacciones docente-alumno. Se expuso a un grupo de estudiantes de psicología a cinco textos con el fin de que leyeran su contenido y posteriormente se les suministró un conjunto de reactivos de dos maneras diferentes: en el modo leer-señalar se presentaron cinco tipos de tareas con algunas modificaciones entre sí, en las que en general se presentaba una pregunta por escrito con opciones de respuesta de las cuales el participante debía señalar la correcta. En el modo leer-escribir se presentaba una pregunta por escrito y se solicitaba una respuesta escrita por parte del participante en cinco tipos de tareas diferentes. Los resultados evidencian que no hubo consistencia entre las ejecuciones de los sujetos en los modos leer-señalar y leer-escribir. Los autores suponen que posiblemente este hallazgo se deba a que tales modos lingüísticos pueden ser funcionalmente equivalentes dada la situación de evaluación o que las tareas no fueron sensibles al modo lingüístico que se deseaba evaluar.

En otro estudio, Mejía y Camacho (2007) evaluaron el efecto de las interacciones con diferentes modos lingüísticos sobre el desempeño académico en 
una clase de geografía. Se formaron dos grupos, uno al cual la clase le exigía interacciones en los modos señalar-observar, leer-escribir y hablarescuchar a través del uso de tecnologías multimedia, y otro al que se le impartió la clase de manera tradicional empleando pizarrón y plumones. Se aplicó inicialmente una preprueba en relación con los contenidos de la clase y posteriormente una posprueba. Las evaluaciones para los dos grupos constaron de cuatro preguntas con opciones de respuesta y seis preguntas abiertas. El Grupo 1, expuesto a interacciones en modos lingüísticos que implicaban el uso de tecnologías multimedia presentó ejecuciones superiores a las del Grupo 2, expuesto a una clase de manera tradicional; aunque en ambos casos se evidenció un aumento en los puntajes obtenidos en comparación con el desempeño logrado en la preprueba. Es decir, los resultados mostraron que en ambos grupos se presentó aprendizaje, pero en el grupo con interacciones en modos lingüísticos variados dicho aprendizaje fue considerablemente mayor.

Por otra parte, Mares, Ribes y Rueda (1993) Ilevaron a cabo un estudio con el objeto de estudiar los efectos de la interacción entre los modos leer-dibujar-escribir-hablar en niños de segundo grado de primaria en la adquisición y transferencia de relaciones identificadas con el empleo de los conectivos para, cuándo y porqué. Primero les pedían que leyeran 10 textos (que incluían dibujos) en los que se describía a varios animales, y posteriormente debían escribir todo lo que sabían respecto de los animales descritos en los textos previamente leídos. Los resultados mostraron buen desempeño de todos los participantes en adquisición pero ninguno logró transferir (que implicaba que le dijeran a un compañero lo que sabían respecto de determinados animales, de los cuales no habían leído, empleando los conectores mencionados). Ante tales resultados, Mares, Guevara y Rueda (1990) replicaron el estudio agregando algunas modificaciones: 1 ) en el entrenamiento se incluyó un dibujo para cada relación descrita, 2) adicionalmente se agregó un dibujo incompleto que el participante debía terminar, y 3) se incluyeron preguntas respecto de cada texto que el sujeto debía contestar de forma oral. Con estos cambios se logró que todos los participantes tuvieran buenos resultados tanto en adquisición como en transferencia, lo que demostró que a mayor cantidad de modos lingüísticos implicados en el entrenamiento el desempeño fue mejor, no solo en la adquisición, sino también en la transferencia de lo aprendido.

Por otra lado, Varela y cols. (Varela, Martínez, Padilla, Ávalos y Jiménez, 2005; Varela, Martínez, Padilla, Ríos y Jiménez, 2004; Varela, et al., 2002; Varela et al., 2006) Ilevaron a cabo una serie de estudios que tenían como objetivo identificar si se observaba primacía del modo lingüístico visual (leer nombres de animales, vegetales u objetos inanimados) respecto del auditivo (escuchar esos nombres) utilizando una tarea de igualación a la muestra de segundo orden en alumnos de educación primaria, secundaria y universitarios, y en todos encontraron que los participantes de menor escolaridad solo lograban buenos desempeños cuando las pruebas incluían un mayor número de estímulos en el modo lingüístico visual, pero los universitarios lograban cumplir el criterio independientemente del modo lingüístico en el que se les presentaran los estímulos. Tales resultados enfatizan dos aspectos, por una parte la primacía del modo lingüístico visual sobre el auditivo, y por otro lado, la interacción entre la experiencia académica y los modos lingüísticos.

Todos los estudios previamente reseñados muestran dos hallazgos centrales: 1) a mayor cantidad de modos lingüísticos implicados mejor desempeño tanto en adquisición como en transferencia, y 2) primacía del modo visual respecto del auditivo. $Y$ lo se hace por lo general en los salones de clase es utilizar métodos de enseñanza-aprendizaje en los que el profesor habla y los alumnos escuchan, es decir, el estudiante se expone a modos lingüísticos auditivos principalmente, y no se suele enseñar empleando modos lingüísticos variados, dado que la estrategia comúnmente utilizada como herramienta pedagógica es que el alumno lea textos, independiente de la materia y contenido que se pretenda enseñarle.

Diversos estudios han mostrado que actualmente los jóvenes utilizan constantemente las TIC's, pero solamente con fines recreativos (Monzón, 2011). Si se lograra trasladar dicho uso a los espacios académicos, el proceso de enseñanza-aprendizaje se vería altamente beneficiado teniendo en cuenta que la tecnología 
permite emplear textos, imágenes, videos, audios, animaciones, simulaciones, hipertextos, etc., (es decir, modos lingüísticos variados), ello propiciaría dejar de emplear como estrategia pedagógica primordial la exposición del alumno al discurso del profesor (es decir, al modo lingüístico auditivo). Una posibilidad, entre varias existentes (Blackboard, WebCT), es emplear como herramienta pedagógica adicional a la enseñanza tradicional la plataforma Moodle, que permite educar a distancia comunicándose con los alumnos por medio de mensajería interna, foros y chat, entre otras opciones. Por sus características es factible subir a la red recursos para enriquecer las clases como textos, vídeos, audios, etc. Tiene la ventaja de que los alumnos pueden acceder a dicha información desde cualquier lugar en el momento que lo deseen; además del uso que se haga de tales materiales en el aula misma; y el contenido se puede dejar en la plataforma el tiempo que se quiera, por lo que puede funcionar como un excelente planificador de los cursos académicos, y además se pueden agregar enlaces a páginas que los estudiantes pueden emplear para enriquecer y complementar su formación (Ros, 2008). Una ventaja adicional de esta plataforma es que es fácil de usar y cuenta con tutoriales sencillos, es gratuita y compatible con varios sistemas operativos (Windows, Linux), y navegadores de internet (Google Chrome, Mozilla Firefox). Esta plataforma puede dividirse en tres grandes rubros: gestión de contenidos, comunicación y evaluación, lo que la hace ideal para emplearse con fines pedagógicos. Y una ventaja adicional, además de las ya mencionadas, es que en caso necesario: por enfermedad, horarios de trabajo, necesidades especiales o circunstanciales, el alumno puede seguir participando en las clases a distancia (Ros, 2008), fomentando la autorregulación del trabajo académico, lo que puede ser una ventaja adicional cuando es deseable que los estudiantes adquieran esa competencia, además de las propiamente académicas.

Las grandes ventajas de las TIC's son su accesibilidad, su facilidad de uso y su adaptabilidad a las necesidades de los usuarios (Coll \& Monereo, 2008). Además, los estudios realizados con el objeto de comparar los efectos de leer textos en papel o multimedia han mostrado que quienes se exponen a esta última modalidad se muestran entusiasmados por la flexibilidad que ello les representa e incluso leen mucho más rápido los textos a los que se les expone, y suelen comentar que les parece más interesante leer en esa modalidad y consideran esa una atmósfera de aprendizaje mejor que la de leer en papel; y en lo relativo al nivel de adquisición logrado con ambos métodos, lo que se ha encontrado es que los resultados suelen ser similares (Demetriadis \& Pombortsis, 2007; Spickard, Alrajeh, Cordray \& Gigante, 2002). Wofford, Spickard y Wofford (2001) Ilevaron a cabo un meta análisis de ocho estudios en los que se comparó leer en papel y en textos multimedia y se encontró el mismo resultado ya mencionado, con la excepción de que en tres de ellos los resultados fueron mejores con los textos multimedia, pero en todos ellos los participantes mencionaron preferir leer los textos multimedia. Por ello los autores de todos los estudios reseñados concluyen que las TIC's son herramientas pedagógicas eficientes y efectivas. Aunque en tales estudios solo se ha analizado uno de los modos lingüísticos, la lectura de textos presentados en dos modalidades: en papel y multimedia. Faltaría realizar comparaciones del desempeño al exponerse a otros modos lingüísticos.

\section{Conclusiones}

La revisión llevada a cabo muestra que no se han analizado de manera sistemática los efectos de los modos lingüísticos en el proceso de enseñanzaaprendizaje mediante las TIC's. La investigación al respecto es fragmentada y desorganizada por lo que la tarea pendiente es, además de seguir realizando estudios acerca del fenómeno, organizarlos en un cuerpo coherente de conocimiento que permita emplear esa información para estructurar planes curriculares en los que se aprovechen las ventajas que las TIC's tienen como herramientas pedagógicas. Las investigaciones anteriores son solo una pequeña muestra del cuerpo de estudios que en la actualidad se están realizando con el fin de intentar dar respuesta a las interrogantes que surgen a partir de la relación entre el conocimiento analítico de la 
propuesta teórica y el conocimiento sintético derivado, aplicado y aplicable a la solución de problemas socialmente relevantes. Ejemplos de tales interrogantes pueden ser: ¿cuáles son las condiciones que posibilitan y probabilizan interacciones lingüísticas variadas y efectivas en sus diversas modalidades? ¿cómo es más efectivo modificar el comportamiento de otros: gesticulándoles, diciéndoles o escribiéndoles, dependiendo de las circunstancias específicas y del contenido particular que se espera transmitir? ¿cuál es la mejor forma de modificar el comportamiento, de seguir instrucciones y/o de comprender: observando, escuchando, leyendo y/o escribiendo? ¿cuáles son las regularidades que dan cuenta de las interacciones con herramientas multimedia en los diferentes niveles de formación educativa y en los diversos campos del saber? ¿qué herramientas multimedia son más útiles dependiendo de las competencias que se espera que el estudiante ejercite? entre muchas otras que la investigación básica y aplicada del área pueden y deben contestar.

\section{Referencias}

Aaron, P. G., \& Malatesha-Joshi, R. (2006). Written language is as natural as spoken language: a biolinguistic perspective. Reading Psychology, 27, 263-311. doi: 10.1080/02702710600846803

Camacho, J. (2006). Dos aspectos en la interacción educativa: la PC y los modos del lenguaje. Boletín electrónico de Investigación de la Asociación Oaxaqueña de Psicología, 3, 104-108. Recuperado de http://www.conductitlan.net/encuentro/24pc_y_lenguaje. pdf

Chafe, W., \& Tannen, D. (1987). The relation between written and spoken language. Annual Review of Anthropology, 16, 383-407. doi: 10.1146/annurev.anthro.16.1.383

Coll, C., \& Monereo, C. (2008). Psicología de la educación virtual. Madrid: Ediciones Morata.

Demetriadis, S., \& Pombortsis, A. (2007). eLectures for Flexible Learning: a Study on their Learning Efficiency. Educational Technology \& Society, 10, 2, 147-157. Recuperado de http://ifets.info/journals/10_2/ets_10_2. pdf\#page $=152$

Fuentes, M., \& Ribes, E. (2001). Un análisis funcional de la comprensión lectora como interacción conductual. Revista Latina de Pensamiento y Lenguaje, 9, 181-212.

Gómez, D. (2005). Transferencia entre modos del lenguaje y niveles de interacción: observar, señalar, escuchar, hablar, leer y escribir. Tesis doctoral no publicada, Universidad de Guadalajara, Jalisco, México.

Hawe, E., Dixon, H., \& Watson, E. (2008). Oral feedback in the context of written language. Australian Journal of Language and Literacy, 31, 43-58. Recuperado de http://www. alea.edu.au/documents/item/71

Irigoyen, J., Jiménez, M., \& Acuña, K. (2006). Evaluación de modos lingüísticos en estudiantes universitarios. Enseñanza e Investigación en Psicología, 11, 81-95. Recuperado de http://www.redalyc.org/articulo. oa?id=29211106

Irigoyen, J., Jiménez, M., \& Acuña, K. (2008). Análisis de la competencia lectora en estudiantes universitarios. Boletín electrónico de investigación de la Asociación Oaxaqueña de Psicología, 4, 84-96. Recuperado de http:// www.conductitlan.net/52_competencia_lectora.pdf

Kantor, J. R. (1967/1978, traducción española). Psicología interconductual. Un ejemplo de construcción científica y sistemática. México: Trillas.

Kaptelinin, V. (2004). Integrating word and picture in the design of educational materials. Mind, Culture, and activity, 11, 173-175. doi: 10.1207/s15327884mca1102_10

Mahony, M., Singson, M., \& Mann, V. (2000). Reading ability and sensitivity to morphological relations. Reading and Writing: An Interdisciplinary Journal, 12, 191-218. doi: 10.1023/A:1008136012492

Mares, G. (2001). La transferencia desde una perspectiva del desarrollo psicológico. En: G. Mares y Y. Guevara (Coords.), Psicología Interconductual. Avances en la investigación básica. Universidad Nacional Autónoma de México: México.

Mares, G., Guevara, Y., \& Rueda, E. (1990, junio). 
Factores que facilitan la adquisición de estilo lingüístico a través de la lectura. Ponencia presentada en el I Encuentro Iberoamericano de Psicología. La Habana, Cuba.

Mares, G., Ribes, E., \& Rueda, E. (1993). El nivel de funcionalidad en lectura y su efecto sobre la transferencia de lo leído. Revista Sonorense de Psicología, 7, 1, 32-43.

Mayer, R. E. (2001). Multimedia learning. New York: Cambridge University Press. doi: 10.1017/CBO9781139164603.002

Mayer, R. E., \& Moreno, R. (1998). A Split-Attention Effect in Multimedia Learning: Evidence for Dual Processing Systems in Working Memory. Educational Psychology Review 90, 312-320. doi: 10.1037//0022-0663.90.2.312

Mejía, M., \& Camacho, J. (2007). Variación de aprendizaje al emplear distintos modos del lenguaje en una interacción académica. Enseñanza e Investigación en Psicología, 12, 277-289. Recuperado de http://www.redalyc. org/articulo.oa?id=29212204

Monzón, L. A. (2011). El blog y el desarrollo de habilidades de argumentación y trabajo colaborativo. Perfiles educativos, 33, 131, 80-93. Recuperado de http://www.redalyc.org/src/ inicio/ArtPdfRed.jsp?iCve=13218531006

Moreno, R., \& Mayer, R. E. (1999). Cognitive principles of multimedia learning: The role of modality and contiguity. Journal of Educational Psychology, 91, 358-368. doi: 10.1037//0022-0663.91.2.358

Moreno, R., \& Mayer, R. E. (2000). A coherence effect in multimedia learning: The case for minimizing irrelevant sounds in the design of multimedia instructional messages. Journal of Educational Psychology, 92, 117-125. doi: 10.1037//0022-0663.92.1.117

Pérez-Almonacid, R., \& Quiroga, L. A. (2010). Lenguaje: Una aproximación interconductual. Bogotá: Corporación Universitaria Iberoamericana.

Petty, M. M. (1974). Relative effectiveness of four combinations of oral and written presentations of job related information to disadvantaged trainees. Journal of Applied Psychology, 59, 105-106. doi: 10.1037/h0035820

Ribes, E. (1989a). La psicología: algunas reflexiones sobre su qué, su cómo, su porqué y su para qué. En J. Urbina (Ed.), El psicólogo (pp. 847-860). México: UNAM.

Ribes, E. (1989b). La inteligencia como comportamiento: un análisis conceptual. Revista Mexicana de Análisis de la Conducta, 15, 5168 (número monográfico). Recuperado de http://www.revistas.unam.mx/index.php/rmac/ article/view/23485

Ribes, E. (1999). Teoría del condicionamiento y lenguaje: un análisis histórico y conceptual. México: Taurus. doi: 968-19-0445-1

Ribes, E. (2006). Competencias conductuales: su pertinencia en la formación y práctica profesional del psicólogo. Revista Mexicana de Psicología, 23, 19-26. Recuperado de http://www.redalyc.org/articulo. oa?id=243020646003

Ribes, E. (2007). Lenguaje, aprendizaje y conocimiento. Revista Mexicana de Psicología, 24,

7-14. Recuperado de http://www.redalyc.org/ articulo.oa?id=243020635002

Ribes, E. (2009). La psicología como ciencia básica. ¿Cuál es su universo de investigación? Revista Mexicana de Investigación en Psicología, 1, 7-19. Recuperado de http:// www.revistamexicanadeinvestigacionenpsicologia.com/index.php/volumen-1-numero2-diciembre-2009

Ribes, E. (2010). Lenguaje ordinario y lenguaje técnico: un proyecto de currículo universitario para la psicología. Revista Mexicana de Psicología, 27, 55-64. Recuperado de http://www.redalyc.org/articulo. oa? id=243016325006

Ribes, E., \& López, F. (1985). Teoría de la conducta. Un análisis de campo y paramétrico. México: Trillas. doi: 978-968-24-1782-5

Ribes, E., Moreno, R., \& Padilla, M. A. (1996). Un análisis funcional de la práctica científica: extensiones de un modelo psicológico. Acta Comportamentalia, 4, 205-235. Recuperado de http://www.revistas.unam.mx/index.php/acom/issue/view/1497/showToc

Ribes, E., \& Varela, J. (1994). Evaluación interactiva del comportamiento inteligente: Desarrollo de una metodología computacional. Revista Mexicana de Análisis de la Conducta, 20, 83-97. Recuperado de http://www.revistas.unam.mx/ index.php/rmac/issue/view/1975/showToc 
Ros, I. (2008). Moodle, la plataforma para la enseñanza y organización escolar. Ikastorratza, e-Revista de didáctica, 2, 3-12. Recuperado de http://www.ehu.es/ikastorratza/2_alea/moodle.pdf

Ryle, G. (1949/2005, traducción española). El concepto de lo mental. Barcelona: Paidós. doi: 116433

Skinner, B. F. (1957). Verbal Behaviour. New York: Appleton Century Crofts. doi: 10.1037/11256

Spickard, A., Alrajeh, N., Cordray, D., \& Gigante, J. (2002). Learning About Screening Using an Online or Live Lecture. Journal of General Internal Medicine, 17, 540-545. doi: 10.1046/j.1525-1497.2002.10731.x

Sweller, J. (2005a). Implications of Cognitive Load Theory for Multimedia Learning. En R. Mayer (Ed.), The Cambridge Handbook of Multimedia Learning (pp. 19-30). Cambridge, Estados Unidos: Cambridge University Press. doi: 10.1017/CBO9780511816819.003

Sweller, J. (2005b). The Redundancy Principle in Multimedia Learning. En R. Mayer (Ed.), The Cambridge Handbook of Multimedia Learning (pp. 159-168). Cambridge, Estados Unidos: Cambridge University Press. doi: 10.1017/ CBO9780511816819.011

Tamayo, J., Ribes, E., \& Padilla, M. A. (2010). Análisis de la escritura como modalidad lingüística. Acta Comportamentalia, 18, 87106. Recuperado de http://www.revistas. unam.mx/index.php/acom/issue/view/1471/ showToc

Varela, J., Martínez, C., Padilla, M. A., Ávalos, M. L., \& Jiménez, B. (2005). Primacía visual IV: Transferencia ante el cambio de dimensión. Revista Apuntes de Psicología, 23, 2, 129-149. Recuperado de http://www.apuntesdepsicologia.es/index.php/revista/article/view/86/88

Varela J., Martínez, C., Padilla, M. A., Ávalos, M., Quevedo, C., Lepe, A., Zepeda, I., \& Jiménez, B. (2002). Primacía visual II: transferencia ante el cambio de la modalidad del estímulo y el modo lingüístico. Acta Comportamentalia, 10, 2, 199-219. Recuperado de http://132.247.146.34/index.php/acom/article/ view/14629

Varela, J., Martínez, C., Padilla, M. A., Ríos, A., Ávalos, M. L., \& Jiménez, B. (2006). Primacía visual: Transferencia ante el cambio de la relación entre estímulos. Revista Latinoamericana de Psicología, 38, 1, 119-135. Recuperado de http://www.scielo.org.co/pdf/rlps/v38n1/ v38n1a08.pdf

Varela J., Martínez, C., Padilla, M. A., Ríos, A., \& Jiménez, B. (2004) ¿Primacía visual? Estudio sobre la transferencia basada en la modalidad de estímulo y en el modo lingüístico. Revista Internacional de Psicología y Terapia Psicológica, 4, 1, 67-91.

Varela, J., \& Quintana, C. (1995). Comportamiento inteligente y su transferencia. Revista Mexicana de Análisis de la Conducta, 21, 47-66.

Wofford, M. M., Spickard, A. W., \& Wofford, J. L. (2001). The Computer-based Lecture. Journal of General Internal Medicine, 16, 464-467. doi: 10.1046/j.1525-1497.2001.016007464.x

Auto-referencias de autor: 7 Auto-referencias de la revista: 0 